\title{
RETENÇÃO DE PESSOAS: UM ESTUDO EM EMPRESA PÚBLICA DO ESTADO DE MINAS GERAIS
}

\section{EMPLOYEE RETENTION: A STUDY IN A PUBLIC COMPANY IN MINAS GERAIS STATE}

Regina Martins Ribeiro Pontifícia Universidade Católica de Minas Gerais - PUC Minas reginasocial@hotmail.com

Simone Costa Nunes Programa de Pós-graduação em Administração da Pontifícia Universidade Católica de Minas Gerais PPGA/PUC Minas sinunes@pucminas.br

\section{Anderson de Souza Sant'Anna Fundação Dom Cabral - FDC anderson@fdc.org.br}

Submissão: $21 / 11 / 2013$ Aprovação: 05/03/2015 


\section{RESUMO}

Este estudo objetivou identificar os fatores que exercem influência sobre a retenção de profissionais em empresa pública do estado de Minas Gerais. Trata-se de estudo de caso descritivo que adotou abordagem quantitativa e qualitativa. A coleta de dados ocorreu por meio da aplicação de questionário, da realização de entrevistas e da análise de documentos da empresa. Os dados apontam que os fatores que englobam investimento em crescimento profissional e ascensão na empresa, bem como ganhos financeiros, são considerados em maior grau de importância para a permanência em uma organização. Tais fatores, no entanto, foram os que obtiveram as piores avaliações. Fica patente que, atualmente, o principal fator de retenção na empresa diz respeito ao fato de seus profissionais gostarem de nela trabalhar. Além disso, a boa imagem da empresa é fator favorável à manutenção de pessoal. No entanto, ficou também evidente a importância de haver atuação efetiva sobre as variáveis cuja avaliação é negativa. Somente assim, será possível permanecer na organização. De maneira contrária, trabalhar na instituição tenderá a ser algo temporário para a maioria dos empregados, que percebem o não atendimento de expectativas relevantes e já buscam instituições mais atrativas por meio de outros concursos.

Palavras-chave: Recursos humanos. Políticas e práticas de retenção de pessoas. Empresa pública. 


\begin{abstract}
This paper aims to identify those factors that have influenced employee retention in a public company in the state of Minas Gerais, Brazil. It is a descriptive case study whose approach is quantitative and qualitative. Data were collected through questionnaires, interviews and an analysis of the company documents. Data have indicated that the factors involving investments in professional growth and career advancement within the company as well as financial gain are considered the most important features for employees to remain in the company. Those factors, however, obtained the worst ratings. It has been clear that the main factor of current retention concerns the fact that employees enjoy working for the company. Furthermore, a good corporate image is a feature in favor of retaining employees. Nevertheless, the importance of taking effective actions in relation to variables whose evaluation was negative was also evident. Conversely, working for such a company is likely to be temporary for most employees, who realize their relevant expectations are not met, and then search for more attractive institutions through public contests.
\end{abstract}

Keywords: Human resources. Employee retention policies and practices. Public companies. 


\section{Introdução}

A transformação nos cenários econômico, tecnológico e de mercado ocorrida nas últimas décadas, bem como a globalização, marcada por forte processo de abertura econômica, alterou os padrões de produção e as características do mercado de trabalho e do trabalho em si (BROCK et al., 2006). Em um contexto em que a informação e o conhecimento tornaram-se artigos valiosos e as mudanças são sempre rápidas, demanda-se excelência organizacional, tanto como condição para o sucesso, quanto como meio de sobrevivência (CANÇADO et al., 2005). Assim, propõe-se uma nova visão a respeito da estratégia organizacional, na qual as áreas de Recursos Humanos (RH) passam a ser vistas também como estratégicas para o alcance dos objetivos das organizações (BROCK et al., 2006).

Configurando tal cenário, as pessoas são apresentadas como fatores de relevância para a manutenção da competitividade, considerando-se, em particular, sua contínua capacidade de contribuição para a geração de valor nas organizações. Em decorrência dessa atitude, repensar as formas de retenção de profissionais de alto desempenho, considerados indispensáveis para a organização, vem-se mostrando uma necessidade (PONTES, 2001). A busca pela manutenção de tais perfis passa, principalmente, pela tentativa de mantê-los motivados e, consequentemente, envolvidos com a visão do negócio e com os resultados da organização, articulando os objetivos de ambas as partes (MENDONÇA, 2002).

No caso das empresas estatais, a gestão de pessoas tem-se concentrado na reestruturação da força de trabalho, seja por meio da composição de seus quadros de pessoal, seja na revisão dos sistemas de remuneração, cargos, carreiras e benefícios.

Os esforços realizados para a manutenção dos empregados nesse setor passam por estabelecer uma linha de trabalho com viés desafiador, aprendizado constante, oportunização de condições para flexibilidade de seus profissionais e manutenção das perspectivas de carreiras (BALASSIANO, 2008).

Tendo por base tal panorama, este artigo dedica-se a apresentar resultados de estudo cujo objetivo foi identificar variáveis que exercem influência sobre a retenção de profissionais no setor público. Para tanto, foi realizada pesquisa de caráter descritivo em empresa pública do estado de Minas Gerais que desenvolve atividades associadas à busca de soluções tecnológicas para o agronegócio. 
Destaca-se a relevância deste estudo, na medida em que busca contribuir com subsídios para a gestão de pessoas em empresas públicas no que se refere à temática da retenção de pessoas. Além disso, acredita-se que o estudo possa ser utilizado pela empresa pesquisada e por outras do setor, gerando reflexões quanto às atuais políticas e práticas adotadas.

Em termos de sua estrutura, o artigo, na sequência desta introdução, apresenta uma fundamentação teórica, dividida em fatores de retenção e a retenção no setor público, em particular; na seção 3, são detalhados os aspectos metodológicos da pesquisa; a seção 4, por sua vez, apresenta os dados e os discute; já na seção 5, encontram-se as considerações finais sobre o estudo, seguidas das referências utilizadas.

\section{Retenção de pessoal}

O modo como as organizações efetuam a gestão de pessoas vem passando, nos últimos vinte anos, por um ritmo intenso de transformações causadas por alterações na organização do trabalho, no relacionamento entre empresa e empregado, e na maneira pela qual os trabalhadores encaram sua relação com o trabalho (DUTRA, 2001).

Tem-se verificado que, nas últimas décadas, com a diminuição da importância conferida às fontes tradicionalmente associadas à obtenção de vantagem competitiva - como a ênfase no produto e na tecnologia de produção -, há maior preocupação com o aspecto humano (FARIA; FERREIRA; CARVALHO, 2008). Isso pelo fato de as organizações dependerem muito mais da forma como administram sua força de trabalho do que da tecnologia e de outros recursos (ALBUQUERQUE, 1999).

Tal ideia é reforçada por Ulrich (1998), quando afirma que o capital intelectual é o único ativo apreciável nas empresas. Enquanto outros ativos, como fábrica, equipamentos e maquinaria, depreciam-se no decorrer do tempo, o capital intelectual é um ativo intangível que, quando mobilizado, cresce firmemente e prospera sempre, tornando-se imprescindível, então, compreender a importância e a utilização desse importante fator humano nas organizações (ULRICH, 1998).

Nesse sentido, a função de apoio, pertencente às áreas que gerem os recursos humanos tendem a assumir novo posicionamento em sua esfera de ação, haja vista a necessidade de valorizar os talentos humanos das organizações (SARSUR, 1999). Logo, faz-se necessária a 
atuação da área de recursos humanos no desenvolvimento das estratégias da organização, na medida em que é ela que cuida com mais propriedade de atrair, manter e desenvolver as competências indispensáveis voltadas para a missão e os objetivos organizacionais (FLEURY; FLEURY, 2001; ALMEIDA, 2008).

Assim sendo, instaura-se a crença de que as empresas que conseguirem desenvolver seus profissionais, torná-los comprometidos e fazê-los perceber seu papel dentro da organização tenderão a obter resultados mais favoráveis (BROCK et al., 2006). No entanto, apesar de ser crescente o número de organizações que reconhecem o capital intelectual como fonte essencial de vantagem competitiva, uma importante questão está em como reter e estimular esse capital, já que os dirigentes empresariais, em sua maioria, assumem o valor da retenção de pessoal qualificado, porém tendem a não saber como articular a manutenção (O’REILLY; PFEFFER, 2001).

Assim, elementos como respeito, confiança, condições de crescimento e desenvolvimento, estabelecimento de desafios e relações positivas na empresa são algumas das perspectivas que passam a ser enfatizadas, notadamente na medida em que as pessoas se envolvem e se comprometem quando veem que suas expectativas são alcançadas e suas necessidades atendidas, considerando o momento presente e futuro (DUTRA, 2001).

Como consequência, demanda-se das organizações que definam de forma clara quais são suas expectativas perante esse pessoal, e quais perspectivas vão ofertar a esse corpo funcional. As empresas devem criar condições para que as pessoas, ao mesmo passo que atendem aos anseios da organização, possam desenvolver-se e sentir-se realizadas em suas atividades (DUTRA, 2001).

Nesse sentido, diversos estudos apontam fatores considerados relevantes para a retenção de pessoas, tais como: desenvolvimento profissional e continuado (CÉSAR; BIDO; SAAD, 2006; DUTRA, 2001), oportunidades de treinamento (MACHADO, 2005; SARSUR; PEDROSA; SANT'ANNA, 2003), flexibilidade no trabalho e carga horária (BRANHAM, 2002; GUBMAN, 1999), ritmo de trabalho (CAMPOS, 2006), variedade de tarefas (ULRICH, 1998), criatividade (CHANG JR. et al., 2007; IZAWA; SILVA; SCHOLTZE, 2006), remuneração e benefícios (FITZ-ENZ, 2001), plano de cargos e salários e critérios de ascensão (CHANLAT, 1995; SARSUR; PEDROSA; SANT'ANNA, 2003), clima organizacional e relacionamento interpessoal (BRANHAM, 2002; MORIN; TONELLI; PLIOPAS, 2007), satisfação pelo trabalho (SANT'ANNA, 2002), reconhecimento 
profissional (BOSQUETTI; ALBUQUERQUE, 2005; TOLEDO, 2006), comunicação interna e abertura para o diálogo (FERREIRA, 2008; PAROLIN; ALBUQUERQUE, 2010), feedback (PAROLIN; ALBUQUERQUE, 2010), relacionamento com a chefia (FERREIRA; FUERTH; ESTEVES, 2006), autonomia (BRANHAM, 2002), nível de desafio (SARSUR; PEDROSA; SANT'ANNA, 2003; VIEIRA; SILVA, 2008), envolvimento e participação nas decisões (BORTOLOTTI, 2010), condições físicas e recursos materiais (PAROLIN; ALBUQUERQUE, 2010) e imagem da empresa (PEDROSA, 2005; SARSUR; PEDROSA; SANT'ANNA, 2003).

Dessa revisão de autores, derivaram as variáveis investigadas neste estudo, tendo-se considerado a observação tecida por Sarsur (1999) de que, não obstante a existência de uma diversidade de estratégias recomendadas para as organizações que buscam manter seu pessoal, não se pode desconsiderar as características e necessidades de cada empresa, para, então, definir a melhor forma de atuação com relação aos recursos humanos.

\subsection{Retenção de pessoal no setor público}

As mudanças empreendidas pela Constituição da República Federativa do Brasil, de 1988, enfatizaram o processo de descentralização de políticas públicas e sociais, propiciando à Administração Pública um viés mais democrático, transparente e com maior controle social. Assim, na década de 1990, a Administração Pública brasileira se vê diante da possibilidade de uma era gerencial e empreendedora, que possa lhe permitir tornar-se mais flexível e eficiente, melhorando a qualidade dos serviços prestados, valorizando o servidor e profissionalizando o setor público (FADUL; SILVA, 2009).

Essas mudanças influenciaram o direcionamento das políticas de recursos humanos no setor público com vistas à geração de resultados e à valoração cada vez maior dos funcionários públicos, visando capacitá-los e torná-los mais motivados. Além disso, procurou-se delegar certa autonomia às instituições públicas no sentido de dar agilidade aos procedimentos (BALASSIANO; COSTA, 2006).

Vale lembrar, porém, que a Administração Pública possui características e demandas próprias em relação às organizações privadas. As empresas estatais, como outras empresas, possuem sua função produtiva e resultados - no caso, sociais - a alcançar, mas assumem 
contornos do Estado, sendo sua estruturação regida pelos planos políticos e econômicos do governo a que estão vinculadas (NUNES; LINS, 2009).

Em relação às especificidades inerentes aos recursos humanos no contexto do setor público, as diferenças já aparecem nos processos de seleção, caracterizados pelo concurso público. Se, de um lado, esse tipo de seleção evita riscos e contestações, de outro, diminui a capacidade de identificação e seleção dos perfis profissionais requeridos às características do cargo e da organização no que concerne, especialmente, às aptidões. Não obstante, restrições dessa natureza poderiam ser compensadas se, de alguma forma, houvesse gerenciamento adequado dos profissionais, buscando melhor aproveitamento de seu potencial. Assim o desafio do Estado é adotar uma política de gestão de pessoas que possa identificar e valorizar o talento de seus empregados (ALMEIDA, 2008).

A gestão planejada de recursos humanos nesse setor, com vistas a manter um quadro funcional habilitado e efetivo, dá-se não apenas por uma atenção cada vez maior dos dirigentes públicos acerca do papel da área, mas também em razão da busca pela modernização do Estado, objetivando cumprir seu papel perante a sociedade (PEREIRA; WILHEIM; SOLA, 1999).

Ainda que paradoxal, em vista do grande fluxo de pessoas que buscam um emprego no setor público, as organizações do Estado enfrentam o desafio de conter a saída de seus profissionais (ALMEIDA, 2008). Apesar de vivenciarem relações menos instáveis de trabalho, eles ainda estão expostos, em muitos casos, a uma política de desvalorização do sujeito. Ela se torna visível por meio do achatamento dos salários e da deterioração das condições de trabalho, evidenciadas na diminuição da quantidade e da qualidade dos materiais de consumo, da manutenção e da aquisição de equipamentos (NUNES; LINS, 2009).

Esses efeitos, somados ao engessamento dos cargos, têm levado profissionais do serviço público a se submeterem a concursos públicos de outras instituições, visando à troca de posição e de nível de carreira, de forma jamais vista (BALASSIANO, 2008). Dessa maneira, muitas pessoas utilizam o concurso público para entrar em uma empresa, temporariamente, enquanto aguardam oportunidades melhores no próprio setor público (ALMEIDA, 2008). Assim, a pretensa flexibilização da alocação dos recursos humanos nas novas carreiras do setor público, notadamente a partir de 2000, não vem alcançando os efeitos desejados (BALASSIANO, 2008). 
Segundo Santos (2006), a Administração Pública brasileira traz, como desafios à gestão de pessoas, a necessidade de se estabelecerem diretrizes gerais a partir da aquisição e do desenvolvimento de competências dos funcionários, bem como a reestruturação de sua força de trabalho, por intermédio da revisão de sistemas de remuneração, cargos, carreiras e benefícios. A gestão de recursos humanos no setor público começa pela aquisição de bons servidores. Para tanto, é preciso que haja políticas de cargos, salários e carreiras que sejam estruturadas e atrativas para estimular a participação e a manutenção de pessoas qualificadas e motivadas (BALASSIANO; COSTA, 2006).

Já se percebem movimentos das áreas de recursos humanos de instituições do setor público com vistas à retenção de seu corpo funcional. Entre os esforços despendidos, encontram-se políticas remuneratórias e de progressão funcional, sistematização de aprendizado constante para a alteração de posições, estabelecimento de desafios profissionais quando do lançamento de novos projetos, prêmios de produtividade e estruturação de avaliações de desempenho funcional (BALASSIANO, 2008).

Não obstante, Balassiano (2008) chama a atenção para a necessidade de avaliação dos reais motivos que levam os talentos a mudarem de cargos e carreiras, pois, sem uma resposta a tal questão, “[...] ações bem intencionadas podem se transformar em verdadeiras falácias [...]" (BALASSIANO, 2008, p. 4).

\section{Aspectos metodológicos da pesquisa}

Esta pesquisa é baseada no método do estudo de caso. Optou-se pelo questionário como instrumento central de coleta de dados. A análise dos dados obtidos foi enriquecida pela realização de entrevistas semiestruturadas e pela análise de documentos pertinentes à empresa. Tendo em vista o objetivo da pesquisa - identificar quais variáveis exercem influência sobre a retenção de profissionais em empresa pública -, o estudo de caso foi considerado mais adequado, pois permite a reunião de informações detalhadas por meio de diferentes técnicas de pesquisa, conforme sugerem Goode e Hatt (1973).

O caso refere-se a uma grande empresa pública criada na década de 1970, no estado de Minas Gerais, cuja sede encontra-se localizada na capital, possuindo também unidades no interior do estado. Trata-se de uma empresa de economia mista que tem como objetivo 
fundamental desenvolver atividades de pesquisa em busca de soluções tecnológicas para o agronegócio. A escolha dessa empresa como objeto deu-se, de um lado, por sua legitimidade e representatividade para o estado de Minas Gerais, e, de outro, por sua preocupação em manter profissionais qualificados em seu quadro.

O estudo foi realizado na sede da instituição, considerando-se que aí se encontram os profissionais que têm papel estratégico no desenvolvimento de projetos e programas da empresa, cujo cargo é denominado Técnico Superior Especializado (TSE).

Com a finalidade de assegurar uma alta qualidade à pesquisa no que diz respeito à validade do constructo e à confiabilidade, a coleta de dados seguiu os princípios propostos por Yin (2001): utilizar várias fontes de evidências que possibilitem o desenvolvimento de linhas convergentes de investigação; criar um banco de dados como forma de organizar e documentar os dados coletados para o estudo de caso, tornando-os disponíveis para consultas posteriores; manter um encadeamento de evidências, permitindo que um observador externo possa perceber que qualquer evidência, proveniente de questões iniciais da pesquisa, leva a conclusões finais do estudo de caso.

No primeiro momento, foram aplicados os questionários. Para a definição do universo de pesquisa, foi adotado o critério de o respondente ser o empregado ou ex-empregado da instituição, estar lotado na sede, ter sido admitido via concurso público do Edital nº 02/2004, e ter prestado o referido concurso para o cargo de TSE. O corte pelo edital de 2004 foi motivado pelo fato de ser esse o último concurso público realizado na empresa e por ser o que apresentou maior rotatividade nos cargos da instituição, em comparação ao concurso anterior, realizado em 1997.

Como resultado, obteve-se um total de 33 profissionais. Entre eles, três foram excluídos, por se entender que sua permanência na empresa foi muito curta (apenas um mês). Além disso, como um dos empregados é pesquisador envolvido neste estudo, entendeu-se que a sua participação também deveria ser excluída. Assim sendo, foram consideradas 29 pessoas, que compuseram a amostra inicial do estudo, sendo 19 empregados e 10 ex-empregados. Retornaram, aos pesquisadores, 26 questionários -18 respondidos pelos empregados atuais e 8 pelos ex-empregados.

Os questionários distribuídos a esse público constavam das mesmas variáveis. A diferença entre eles era apenas quanto à forma como se perguntou sobre elas, conforme apresentado no Quadro 1. 
Quadro 1 - Exemplo de questões presentes nos questionários

\begin{tabular}{|l|l|l|lr|}
\hline Respondentes & $\begin{array}{l}\text { Tipo de } \\
\text { questão }\end{array}$ & Objetivo das perguntas & $\begin{array}{l}\text { Exemplo de perguntas do questionário } \\
\text { (variável no exemplo: desenvolvimento } \\
\text { profissional) }\end{array}$ \\
\hline $\begin{array}{l}\text { Empregados } \\
\text { atuais }\end{array}$ & 1 & $\begin{array}{l}\text { Avaliar a percepção do indivíduo } \\
\text { quanto às condições ofertadas } \\
\text { pela organização }\end{array}$ & $\begin{array}{l}\text { Como avalio as possibilidades de } \\
\text { desenvolvimento profissional oferecidas pela } \\
\text { organização? }\end{array}$ \\
\cline { 2 - 5 } & 2 & $\begin{array}{l}\text { Avaliar a percepção do indivíduo } \\
\text { quanto à contribuição do fator } \\
\text { para a sua permanência em uma } \\
\text { organização }\end{array}$ & $\begin{array}{l}\text { Esse fator contribui para a minha permanência } \\
\text { em uma organização? }\end{array}$ \\
\hline $\begin{array}{l}\text { Ex- } \\
\text { empregados }\end{array}$ & 1 & $\begin{array}{l}\text { Avaliar a percepção do indivíduo } \\
\text { quanto às condições ofertadas } \\
\text { pela organização }\end{array}$ & $\begin{array}{l}\text { Como avalio as possibilidades } \\
\text { desenvolvimento profissional que a organização } \\
\text { oferecia quando eu era seu empregado? }\end{array}$ \\
\cline { 2 - 6 } & 2 & $\begin{array}{l}\text { Avaliar a percepção do indivíduo } \\
\text { quanto à contribuição do fator } \\
\text { para a sua permanência em uma } \\
\text { organização }\end{array}$ & $\begin{array}{l}\text { Esse fator contribui para a minha permanência } \\
\text { em uma organização? }\end{array}$ \\
\hline
\end{tabular}

Fonte: Dados da pesquisa.

As questões do tipo 1 foram respondidas por meio de uma escala do tipo likert de 7 pontos, sendo: 1 = péssimo, $2=$ muito ruim, $3=$ ruim, $4=$ regular, $5=$ bom, $6=$ muito bom, 7 = excelente. A escala likert construída para as questões do tipo 2 tem 5 pontos: $1=$ totalmente, $2=$ muito, $3=$ moderadamente, $4=$ pouco, $5=$ nada.

Os dados obtidos por meio dos questionários passaram por tratamento e análise estatística. Buscando a compreensão das respostas, a escala de importância para influência e permanência foi transformada pela subtração dos valores centrais 4 e 3, para que oscilassem de -1 a 1, sendo tal transformação sugerida por Gelman e Hill (2007). Após articulá-las em seus valores centrais, as escalas de influência e permanência foram divididas por 3 e 2, respectivamente. Logo, os valores positivos da escala significam que o indivíduo avalia o fator como importante, e os valores negativos, como não importantes. Esses níveis receberam pesos numéricos, de modo que um tratamento quantitativo fosse usado sem prejuízo para a linha qualitativa da pesquisa. Assim, para comparar a média das variáveis dentro de cada escala, foi utilizado o intervalo de $95 \%$ de confiança bootstrap, fundamentado em Efron e Tibshirani (1993).

Como o universo e o tamanho da amostra mostraram-se pequenos, consideraram-se marginalmente significativos os testes estatísticos com p-valor entre 0,5 e 0,10. O software utilizado na análise foi R versão 2.11.1. 
No segundo momento, visando enriquecer os achados obtidos via questionários, foram realizadas entrevistas semiestruturadas e em profundidade junto aos profissionais, respondentes da primeira etapa da pesquisa. As entrevistas ocorreram durante o horário de trabalho, em uma sala de reuniões da própria empresa. Todas elas foram gravadas e transcritas, sendo o tempo médio de duração de 30 minutos. O tratamento e a análise dos dados obtidos ocorreram por meio da técnica de análise de conteúdo, considerando-se as categorias presente no Quadro 2.

Quadro 2 - Categorias de análise

Fonte: Dados da pesquisa.

\begin{tabular}{|l|l|}
\hline Número & Categoria \\
\hline 1 & Como é trabalhar na empresa \\
\hline 2 & Pontos fortes da empresa \\
\hline 3 & Pontos fracos da empresa \\
\hline 4 & Expectativas profissionais ao entrar na empresa \\
\hline 5 & Atendimento das expectativas \\
\hline 6 & Desejo de carreira na empresa \\
\hline 7 & Reforço para permanecer na empresa \\
\hline
\end{tabular}

Nos dois momentos, foram analisados documentos da empresa com a finalidade de obter informações sobre a admissão e a demissão de empregados no período estabelecido, e sobre as políticas e práticas de gestão de pessoas adotadas.

\section{Apresentação e discussão dos resultados}

Dos 26 participantes da pesquisa, 69,20\% são empregados e 30,80\% estiveram vinculados à empresa no período compreendido entre 2005 e 2010. Entre eles, destaca-se o seguinte perfil: $53,80 \%$ pertencem ao sexo masculino; pouco mais da metade possui filhos; predomina a faixa etária entre 26 e 30 anos $(42,30 \%)$, seguida daqueles que estão entre 31 e 35 anos (23,10\%); 53,80\% são casados e 42,30\% são solteiros; a maioria $(69,20 \%)$ possui pós-graduação lato sensu finalizada $(69,20 \%)$ ou em curso $(15,40 \%)$.

Em termos dos fatores de atração, a busca pela estabilidade no emprego é indicada como fator prioritário para a escolha da organização para 80,80\% dos respondentes. Além disso, a maioria $(76,90 \%)$ continua prestando concursos para outros órgãos e setores do funcionalismo público, corroborando os dados encontrados em trabalhos como o de 
Balassiano (2008) e Almeida (2008). Segundo esses autores, diversos fatores como o achatamento salarial e o engessamento de carreiras têm levado empregados de empresas públicas a continuar prestando concurso público, em busca de melhores oportunidades.

Quanto ao tempo de trabalho na empresa, verificou-se, entre os desligados, que a maior parte havia permanecido até um ano na empresa (87,50\%). Aqueles que permanecem como empregados estão, em sua maioria, entre dois e cinco anos $(83,3 \%)$ trabalhando na empresa.

Os dados obtidos por meio dos questionários são apresentados nos gráficos 1,2 e 3. O Gráfico 1 permite comparar o valor de cada variável para os fatores de influência na retenção (avaliação feita pelos respondentes acerca das variáveis na empresa estudada). Cada ponto corresponde à posição que cada variável foi avaliada. Assim, tem-se que, quanto mais próximo de 1.0 estiver o ponto da variável, melhor avaliada ela foi. E, do contrário, quanto mais próximo o ponto da variável estiver de -1.0 , menor foi a avaliação recebida por ela. Lembrando que 0.0 é o valor central considerado nulo.

As variáveis da empresa (cerca de $20 \%$ do total) que foram avaliadas de forma mais positiva, em ordem decrescente, são: relacionamento interpessoal, relacionamento com a chefia, imagem da empresa, ritmo de trabalho, previdência privada, satisfação pelo trabalho e flexibilidade no trabalho.

As variáveis que evidenciam as avaliações mais baixas são em ordem decrescente: plano de cargos, critérios de ascensão, retenção de pessoal, condições físicas, salário, remuneração justa, desenvolvimento profissional e oportunidade de treinamento.

Gráfico 1 - Intervalo de confiança bootstrap percentílico para os fatores de influência 


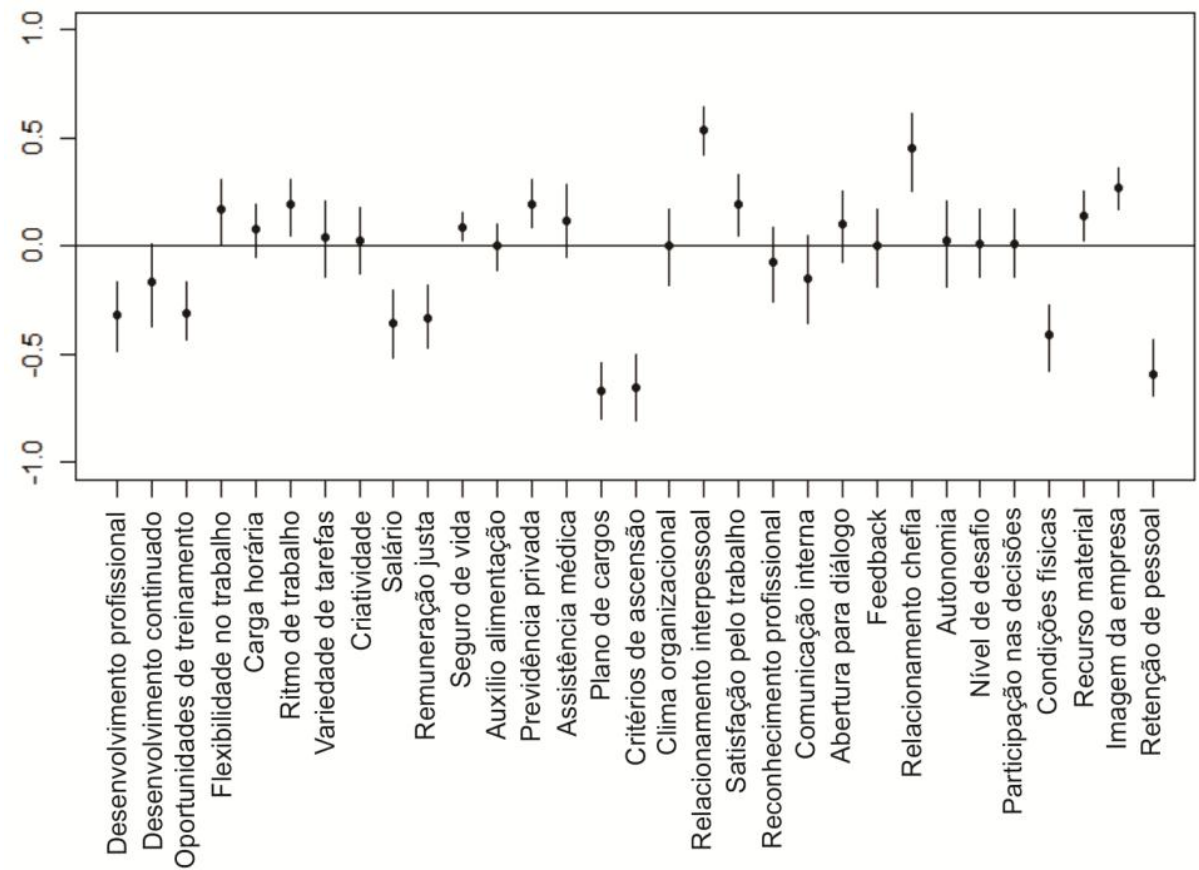

Fonte: Dados da pesquisa.

A partir do Gráfico 2, é possível comparar o valor de cada variável para os fatores de permanência (o quanto a variável contribui para a retenção deles em uma empresa). Cada ponto corresponde à posição que cada variável foi considerada em termos de importância para a permanência dos pesquisados em uma empresa. Assim, tem-se que, quanto mais próximo de 1.0 estiver o ponto da variável, mais importante ela é para a permanência. Do contrário, quanto mais próximo o ponto da variável estiver de -1.0, menos importante ela é para a permanência dos pesquisados em uma empresa. Lembrando que 0.0 é o valor central considerado nulo.

As variáveis (cerca de $20 \%$ do total) que se destacaram como mais importantes para a permanência em uma organização são em ordem decrescente: plano de cargos, critérios de ascensão, retenção de pessoal, desenvolvimento profissional, reconhecimento profissional, salário e desenvolvimento continuado. Com relação às variáveis consideradas menos importantes para a permanência em uma empresa, tem-se, em ordem decrescente: seguro de vida, previdência privada, comunicação interna, carga horária, ritmo de trabalho e condições físicas.

Gráfico 2 - Intervalo de confiança bootstrap percentílico para os fatores de permanência 


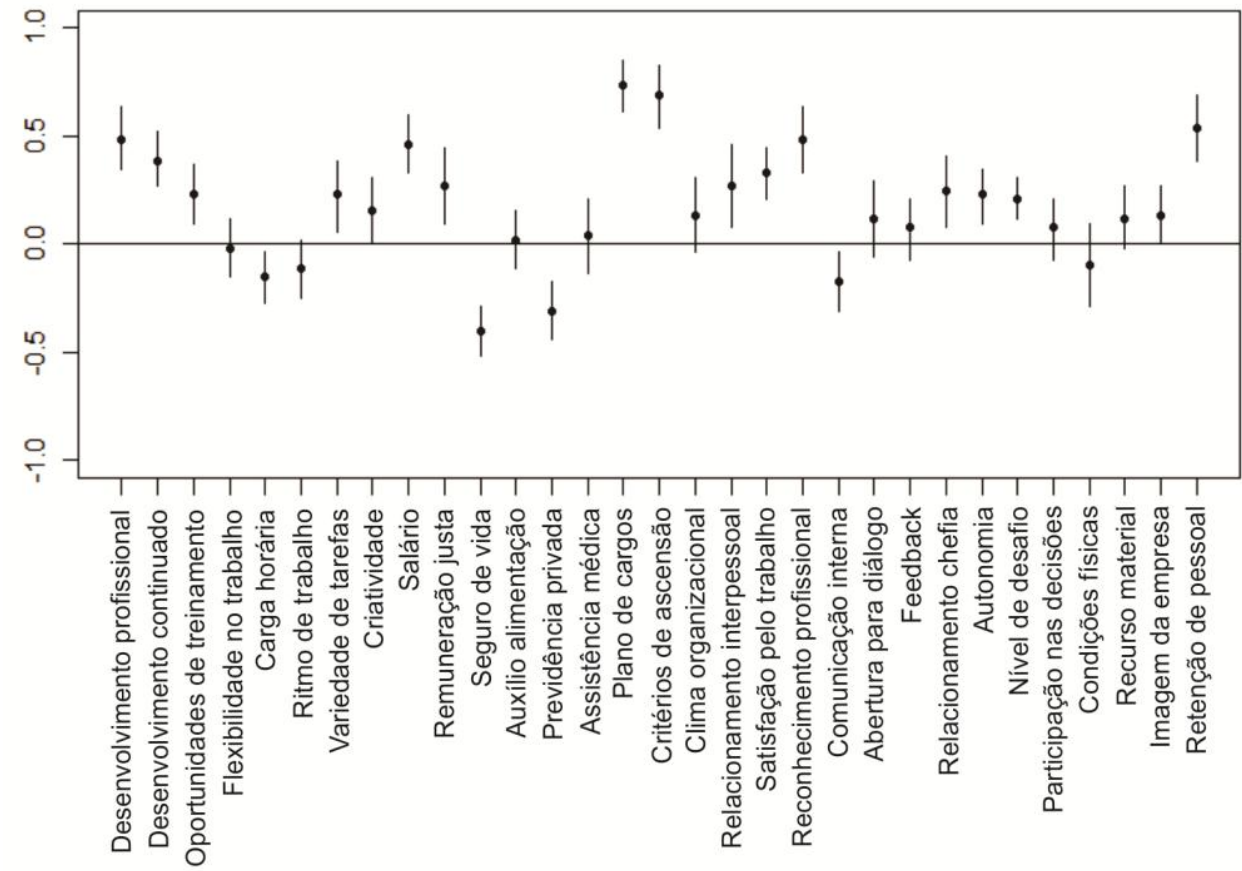

Fonte: Dados da pesquisa.

Com a finalidade de integrar os dados dos gráficos já apresentados (Gráfico 1 e Gráfico 2), segue um comparativo entre os fatores de influência e os de permanência. Assim, podem-se perceber valores opostos, o que denota, de um lado, que a variável presente na empresa estudada foi mal avaliada, porém, considerada importante para a permanência em uma instituição. Ou, de outro lado, que a variável foi bem avaliada, porém, não foi considerada tão importante para a permanência em uma organização.

No Gráfico 3, pode ser verificado que as variáveis correlacionadas negativamente de forma significativa são o plano de cargos, critérios de ascensão, retenção de pessoal, salário, desenvolvimento profissional, reconhecimento profissional, desenvolvimento continuado, oportunidades de treinamento e remuneração justa. Logo, neste caso, tais variáveis obtiveram baixa avaliação por parte dos entrevistados, mas mostraram-se importantes para a sua permanência em uma organização.

São correlacionadas positivamente de forma significativa, ou seja, além de serem bem avaliadas, são variáveis valorizadas no sentido de auxiliar na retenção dos empregados as seguintes: relacionamento interpessoal, satisfação pelo trabalho, relacionamento com a chefia, recurso material e imagem da empresa (Gráfico 3). 
Gráfico 3 - Gráfico de linhas médias dos escores entre influência e permanência

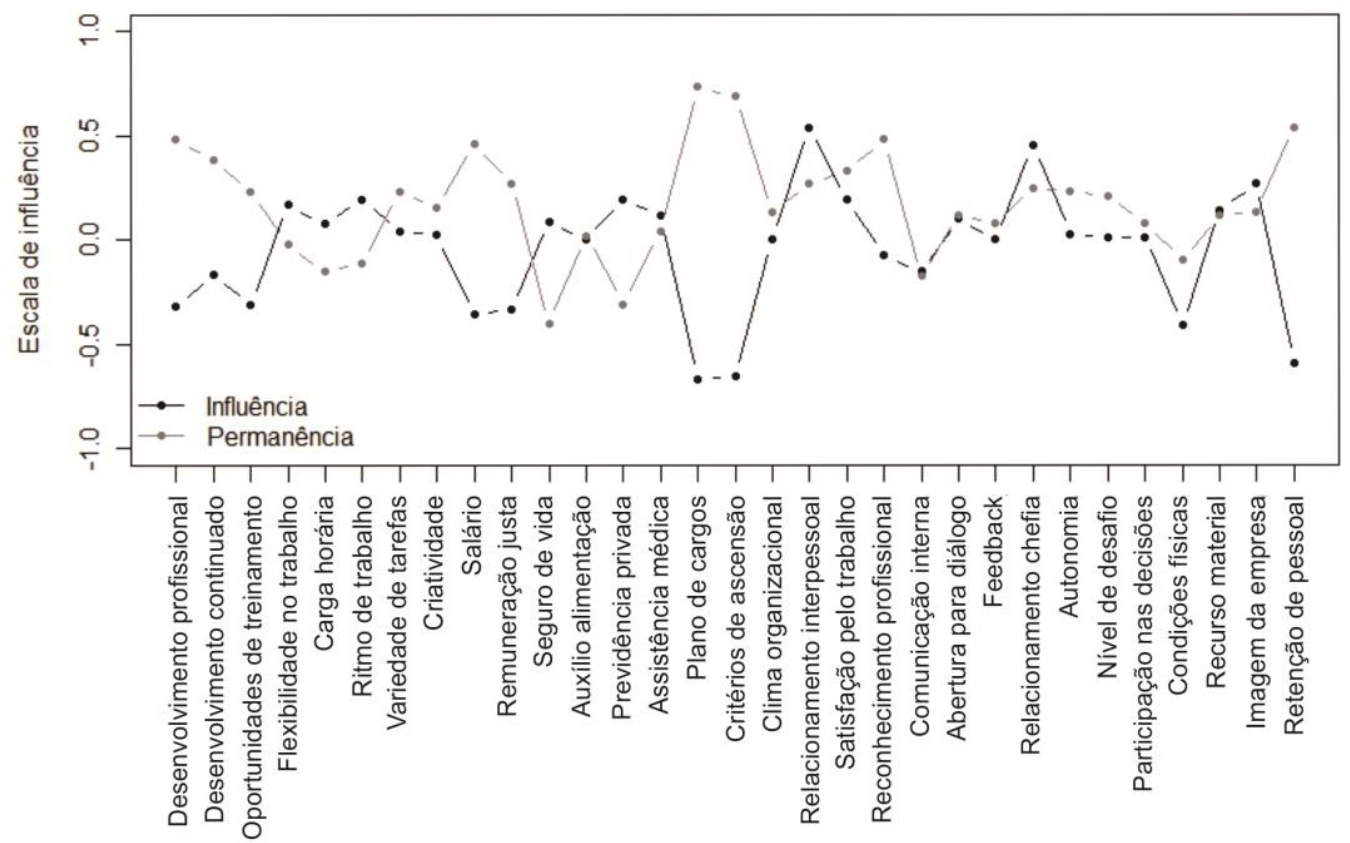

Fonte: Dados da pesquisa.

Com vistas a aprofundar o conhecimento sobre as condições para a retenção de pessoal na empresa analisada, foram também realizadas entrevistas com alguns dos atuais empregados, resultando nos achados apresentados adiante.

Questionados sobre como é trabalhar na empresa em estudo, a maioria dos entrevistados disse gostar da empresa, sendo o relacionamento interpessoal o principal fator de contentamento. Conforme afirmaram os entrevistados: “[...] Eu gosto das pessoas, da convivência, dos meus colegas [...]" (E3).

Não obstante, alguns pontos, como as políticas de desenvolvimento profissional, a valorização e o reconhecimento por parte da empresa, são considerados como limitadores da satisfação profissional, influenciando negativamente no desejo de permanência na empresa. $\mathrm{O}$ trecho da fala a seguir espelha a visão dos entrevistados: "As pessoas saem da empresa porque passam em outros concursos públicos e vão embora, já que aqui dentro não tem um incentivo ao desenvolvimento profissional e contínuo" (E8).

As informações corroboram achados apresentados no Gráfico 1, que mostra a variável relacionamento interpessoal mais bem avaliada e o desenvolvimento e reconhecimento 
profissional entre aquelas variáveis que foram avaliadas pior. As duas últimas, por sua vez, foram consideradas importantes para a permanência dos pesquisados em uma organização.

A importância dada ao reconhecimento profissional pode ser explicada em conformidade com Toledo (2006), que defende que, quando o trabalho profissional é reconhecido, seus esforços adquirem sentidos. Quanto ao desenvolvimento, Tanure, Evans e Pucik (2007) defendem que investir no desenvolvimento dos empregados é uma das estratégias importantes utilizadas para a sua retenção e para assegurar o seu comprometimento com os resultados organizacionais.

Alguns desses aspectos foram ratificados nas questões que tratavam dos pontos fortes e fracos da instituição pesquisada. Entre os pontos fortes, estão o relacionamento com os colegas, o clima organizacional, a estabilidade no emprego e os benefícios complementares. Novamente, o que se evidencia com mais intensidade é o relacionamento interpessoal, tornando-se uma vantagem para a empresa, já que, conforme afirmado por Yamashita (2006), a empresa tem muito a ganhar ao proporcionar um ambiente agradável e de integração entre os empregados e deles com a própria empresa. Entretanto, deve-se ter em vista que, apesar de o relacionamento interpessoal ter sido considerado importante para a permanência, outras variáveis ligadas ao desenvolvimento, à carreira e à remuneração mostraram-se mais relevantes quando se trata de permanecer em uma organização.

Outra questão apontada e que merece destaque são os benefícios oferecidos. Para Marras (2000), eles são capazes de facilitar e melhorar a qualidade de vida dos funcionários, além de complementar o sistema de salários, por incluírem uma variedade de facilidades e vantagens ofertadas pela organização, como assistência médica, seguro de vida, alimentação subsidiada e plano de previdência.

A estabilidade no emprego também apareceu em destaque na fala dos entrevistados, reafirmando dado anterior, que mostra essa variável como prioritária na escolha de uma organização, segundo a maior parte dos participantes da pesquisa: "A tranquilidade da estabilidade no emprego; plano de saúde e odontológico, previdência privada, seguro de vida; o próprio ambiente de trabalho [...]" (E6).

Em relação aos pontos negativos apontados pelos respondentes, destaca-se o plano de cargos e salários, que é considerado ruim e defasado em relação às atuais demandas dos profissionais. Assim, verifica-se a insatisfação dos entrevistados com a remuneração, especialmente no tocante ao salário, e a falta de reconhecimento profissional, corroborando os 
dados obtidos por meio dos questionários. $\mathrm{O}$ resultado da insatisfação pode vir a ser o comprometimento da vontade de permanência na empresa.

A satisfação com o reconhecimento financeiro é abordada por Gubman (1999), para quem esse é um dos fatores que determinam o engajamento dos empregados com a organização.

Outro achado da pesquisa refere-se à existência de insatisfação dos empregados diante do paradoxo instalado pela contratação e/ou promoção de profissionais que guardam algum tipo de relação com a diretoria da empresa (ou autoridades do governo). Isso denota que fatores externos são utilizados como elementos diferenciadores, contrariamente ao desempenho dos empregados, gerando desmotivação junto àqueles que se dedicam à instituição. Segundo os entrevistados, “[...] muita gente aqui recebe as coisas porque é amigo de fulano de tal, e isso é totalmente desmotivante." (E2).

Ao buscar conhecer quais as expectativas desses empregados antes de entrarem na instituição e se foram alcançadas, tem-se que as expectativas não chegaram a ser atendidas. $\mathrm{O}$ reconhecimento e o crescimento profissional são, em grande medida, as principais perspectivas que os respondentes tinham em mente ao entrar na empresa. Os entrevistados concordam que: "[...] A gente tem expectativa de melhorar, de crescer profissionalmente, mas aqui é muito difícil por causa da questão política" (E2).

A esse respeito, tem-se o alerta de Pedrosa (2005), para quem as divergências de expectativas são geradoras de frustração e contribuem significativamente para a decepção e, logo, para a não permanência dos empregados na empresa.

Também ficou evidente que muitos profissionais têm atribuições não compatíveis com suas funções e possuem cargos que subutilizam seu potencial: “[...] Minhas expectativas não foram alcançadas. Fui contratada como profissional de curso superior, mas sempre trabalhei como profissional de nível médio, realizando trabalhos operacionais e rotineiros" (E4).

Esta questão é discutida por Almeida (2008), segundo a qual a exigência de um perfil profissional ideal, sobretudo no que se refere ao grau de instrução, muitas vezes não corresponde à realidade, podendo levar à subutilização dos profissionais em atividades não condizentes com os requisitos, e maior marginalização das pessoas.

Sobre o seu futuro profissional na empresa pesquisada, os respondentes, em maioria, disseram que não desejam permanecer na instituição durante longo prazo, por não haver oportunidades de crescimento profissional e de carreira. Contudo, mudanças efetivas e 
pontuais, como desenvolvimento e planejamento de um plano de cargos e salários, podem fazê-los mudar de opinião. Segundo os entrevistados: "Não. Porque a empresa não valoriza os empregados, ela não possui um Plano de Cargos e Salários adequado e justo. Ela não investe em desenvolvimento, em treinamento [...]" (E5).

Tais afirmações alinham-se aos índices obtidos na caracterização dos respondentes, em que aproximadamente $77 \%$ indicam que ainda prestam concursos. Isso não contradiz, no entanto, os $80 \%$ que têm estabilidade como prioridade, já que a saída se dá em busca de outras instituições públicas. Além disso, ratificam-se os dados obtidos por meio dos questionários, em que as três variáveis mais importantes para a permanência em uma organização são o plano de cargos e salários, os critérios de ascensão e a retenção de pessoal.

Questionados sobre o que os levaria a permanecer na empresa, os entrevistados tenderam a reforçar a importância de a organização atuar sobre as variáveis já citadas como pontos fracos: "Se a empresa mudasse, criasse critérios claros e justos de crescimento e oportunidades de desenvolvimento, eu gostaria de ficar, pois gosto daqui como empresa" (E1).

Alguns aspectos foram enfatizados, como o reconhecimento profissional, as oportunidades de crescimento, as melhorias no plano de cargos e salários, a adoção de avaliação de desempenho, a transparência nos processos e o estabelecimento de canais de comunicação mais efetivos.

Faria, Ferreira e Carvalho (2008) apontam que, para reter seus profissionais, a organização deve conceder um pacote de benefícios materiais e imateriais a seus empregados, elaborado para torná-la atraente diante da concorrência. Motta (2004) defende ainda que fatores relacionados com responsabilidade, desenvolvimento e reconhecimento são bastante relevantes para obter um grau de satisfação elevado e, assim, influenciar positivamente na retenção de pessoal.

Autores como Sarsur (1999), Pedrosa (2005) e Yamashita (2006) reforçam tais perspectivas. Segundo eles, programas de integração, clara definição do que se espera do corpo funcional, programa de treinamento e desenvolvimento continuado, possibilidades de crescimento profissional, reconhecimento do valor dos empregados e gestão de carreira são práticas determinantes e que influenciam, de forma significativa, na retenção de pessoal. 


\section{Considerações finais}

A pesquisa evidenciou o grande número de respondentes que busca a estabilidade no emprego como prioridade na escolha de uma organização. Percebe-se, a partir daí, a atração exercida pelo setor público, tendo em vista a possibilidade de manutenção do emprego (estabilidade), independentemente de possíveis crises (externas ou afeitas diretamente à organização), de mudanças organizacionais ou de outros fatores relacionados ao perfil do empregado, que poderiam desaguar em demissão.

Não obstante a maioria dos participantes também afirmar que ainda presta concursos para outros órgãos públicos, entende-se que a estabilidade garantida pela empresa pesquisada, por si só, não proporciona a retenção. Fica evidente que os fatores que englobam o investimento em crescimento profissional e a ascensão na empresa, bem como os ganhos financeiros, são considerados em maior grau de importância para a permanência em uma organização. Esses fatores, no entanto, foram os que obtiveram as piores avaliações pelos participantes da pesquisa. Ao ingressar na empresa, havia expectativas de crescimento e reconhecimento profissional, o que não foi atendido, segundo percebem alguns empregados.

Outra evidência relevante refere-se ao fato de que os respondentes consideram que a empresa, de maneira geral, tem problemas com a retenção de pessoas. Isso foi observado nas respostas que colocaram essa variável entre as três que tiveram pior avaliação. Logo, considerando-se que as pessoas envolvem-se e comprometem-se com o trabalho quando veem suas expectativas e necessidades atendidas, é possível que a instituição venha a ter dificuldades para reter seus empregados.

Atualmente, o que parece ser o principal fator de retenção de seus profissionais diz respeito ao fato de eles gostarem de nela trabalhar, considerando o relacionamento estabelecido entre as pessoas, o que inclui a chefia. Além disso, a sua imagem é também fator favorável à organização no sentido de manter seus profissionais. No entanto, os entrevistados reforçaram a importância de haver uma atuação efetiva sobre as variáveis cuja avaliação é negativa. Somente assim, declaram ser possível permanecer na organização. De maneira contrária, trabalhar na instituição tenderá a ser algo temporário para a maioria dos empregados, que percebem o não atendimento de expectativas relevantes e já buscam instituições mais atrativas por meio de outros concursos. 
Por fim, cabe registrar que existem questões que se relacionam ao setor, como a inserção em posições de destaque e a promoção de pessoas por apadrinhamento político, conforme evidenciaram os entrevistados. Além disso, a empresa estudada depende de um alinhamento com as políticas do governo estadual e nem sempre pode agir de forma deliberada. A consequência disso, no curto e médio prazo, poderá ser a manutenção das condições indesejáveis, contribuindo para a saída dos profissionais que, no caso estudado, têm papel estratégico no desenvolvimento dos programas e projetos da empresa.

Como limitação deste estudo, pode ser citado o tamanho da amostra. Além disso, não se pode tomar este trabalho como uma referência absoluta para o estudo do setor público, já que se trata de estudo de caso único. Contudo, destacam-se aspectos relevantes que ensejam a reflexão sobre a gestão de pessoas, notadamente sobre a retenção de pessoas, podendo contribuir com a empresa estudada, bem como com outras organizações do setor público.

\section{Referências}

ALBUQUERQUE. L. G. Estratégia de recursos humanos e competitividade. In: VIEIRA, M. M. F.; OLIVEIRA, L. M. B. (Org.). Administração contemporânea: perspectivas estratégicas. São Paulo: Atlas, 1999.

ALMEIDA, W. Captação e seleção de talentos: repensando a teoria e a prática. São Paulo: Atlas, 2008.

BALASSIANO, M. Planejamento prospectivo de carreiras no setor público. In: CONGRESO INTERNACIONAL DEL CLAD SOBRE LA REFORMA DEL ESTADO Y DE LA ADMINISTRACIÓN PÚBLICA, 13., 2008, Buenos Aires. Anais... Buenos Aires: [s.n.], 2008.

Atlas, 2006.

; COSTA, I. S. A. Gestão de carreiras: dilemas e perspectivas. São Paulo:

BORTOLOTTI, S. L. V. et al. Mudança organizacional: informação, envolvimento e participação para o sucesso da transformação institucional. In: SIMPÓSIO DE EXCELÊNCIA EM GESTÃO E TECNOLOGIA, 7., 2010. Anais... Resende: Associação Educacional Dom Bosco, 2010. 
BOSQUETTI, M. A.; ALBUQUERQUE, L. G. Gestão estratégica de pessoas: visão do RH x visão dos clientes. In: ENCONTRO NACIONAL DOS PROGRAMAS DE PÓSGRADUAÇÃO EM ADMINISTRAÇÃO, 29., 2005, Brasília. Anais... Rio de Janeiro: ANPAD, 2005.

BRANHAM, L. Motivando as pessoas que fazem a diferença. Rio de Janeiro: Campus, 2002.

BROCK, H. et al. O papel estratégico do RH. In: SIMPÓSIO DE EXCELÊNCIA EM GESTÃO E TECNOLOGIA, 3., 2006. Anais... Resende: Associação Educacional Dom Bosco, 2006.

CAMPOS, I. C. M. Diagnóstico de transtornos mentais e comportamentais e relação com o trabalho de servidores públicos estaduais. 2006. 112f. Dissertação (Mestrado em Psicologia) - Programa de Pós-graduação em Psicologia, Universidade Federal de Santa Catarina, Florianópolis, 2006.

CANÇADO, V. L. et al. Novos papéis de recursos humanos: velhas fórmulas em novas embalagens? In: ENCONTRO NACIONAL DOS PROGRAMAS DE PÓS-GRADUAÇÃO EM ADMINISTRAÇÃO, 29., 2005, Brasília. Anais... Rio de Janeiro: ANPAD, 2005.

CÉSAR, A. M. R.; BIDO, D. S.; SAAD, S. M. "O discurso se aplica na prática?": uma discussão sobre o papel estratégico da área de recursos humanos. In: ENCONTRO NACIONAL DE PROGRAMAS DE PÓS-GRADUAÇÃO EM ADMINISTRAÇÃO, 30., 2006, Salvador. Anais... Salvador: [s.n.], 2006.

CHANG JR., J. et al. Variáveis antecedentes ao comprometimento organizacional afetivo e sua relação com o desempenho: uma abordagem estratégica baseada no modelo ResourceBased View - RBV. In: ENCONTRO NACIONAL DE PROGRAMAS DE PÓSGRADUAÇÃO EM ADMINISTRAÇÃO, 31., 2007, Rio de Janeiro. Anais... Rio de Janeiro: ANPAD, 2007.

CHANLAT, J. F. Quais carreiras e para qual sociedade? (I). Revista de Administração de Empresas, São Paulo, v. 35, n. 6, p. 67-75, nov./dez. 1995.

DUTRA, J. S. Gestão de pessoas. São Paulo: Atlas, 2001.

EFRON, B., TIBSHIRANI, R. An introduction to the bootstrap. [S.1.]: Chapman and Hall, 1993. 
FADUL, E. M. C.; SILVA, M. A. M.-A. Limites e possibilidades disciplinares da administração pública e dos estudos organizacionais. Revista de Administração Contemporânea, Curitiba, v. 13, n. 3, p. 351-365, jul./ago. 2009.

FARIA, M. D.; FERREIRA, D. A.; CARVALHO, J. L. F. Responsabilidade social empresarial: um fator de atração para novos talentos? In: ENCONTRO NACIONAL DE PROGRAMAS DE PÓS-GRADUAÇÃO EM ADMINISTRAÇÃO, 32., 2008, Rio de Janeiro. Anais... Rio de Janeiro: ANPAD, 2008.

FERREIRA, A. M. Políticas e práticas de gestão de pessoas como fatores de retenção de jovens talentos: um estudo com trainees de empresa brasileira do setor siderúrgico. 2008. Dissertação (Mestrado) - Pontifícia Universidade Católica de Minas Gerais, Programa de Pós-Graduação em Administração, Belo Horizonte, 2008.

FERREIRA, A.; FUERTH, L. R.; ESTEVES, R. C. P. M. Fatores de motivação no trabalho: o que pensam os líderes. In: ENCONTRO NACIONAL DE PROGRAMAS DE PÓSGRADUAÇÃO EM ADMINISTRAÇÃO, 30., 2006, Salvador. Anais... Rio de Janeiro: ANPAD, 2006.

FITZ-ENZ, J. Retorno do investimento em capital humano. São Paulo: Makron Books, 2001.

FLEURY, A.; FLEURY, M. T. L. Estratégias empresariais e formação de competências: um quebra-cabeça caleidoscópico da indústria brasileira. São Paulo: Atlas, 2001.

GELMAN, A.; HILL, J. Data analysis using regression and multilevel/hierarchical models. New York: Cambridge University Press, 2007.

GOODE, W. J.; HATT, P. K. Métodos em pesquisa social. 4. ed. São Paulo: Nacional, 1973.

GUBMAN, E. L. Talento: desenvolvendo pessoas e estratégias para obter resultados extraordinários. 8. ed. São Paulo: Campus, 1999.

IZAWA, M. C.; SILVA, S. A.; SCHOLTZE, S. As políticas e práticas de retenção de talentos em uma organização varejista. In: SEMINÁRIOS EM ADMINISTRAÇÃO - SEMEAD FEA/USP, 9., 2006, São Paulo. Anais... São Paulo: USP, 2006. 
MACHADO, G. M. Fatores de retenção e desligamento de pessoas numa empresa de supermercados em Fortaleza. 2005. Dissertação (Mestrado) - Faculdade de Economia, Administração, Atuária e Contabilidade, Universidade Federal do Ceará, Fortaleza, 2005.

MARRAS, J. P. Administração de recursos humanos: do operacional ao estratégico. São Paulo: Futura, 2000.

MENDONÇA, M. C. F. Retenção de talentos por meio de reconhecimento e recompensas. 2002. Dissertação (Mestrado em Administração) - Escola Brasileira de Administração Pública e de Empresas, Fundação Getúlio Vargas, Rio de Janeiro, 2002.

MORIN, E.; TONELLI, M. J.; PLIOPAS, A. L. V. O trabalho e seus sentidos. Revista Psicologia e Sociedade, Porto Alegre, Edição Especial, v. 19, p. 47-56, 2007.

NUNES, A. V. L.; LINS, S. L. B. Servidores públicos federais: uma análise do prazer e sofrimento no trabalho. Revista Psicologia: Organizações e Trabalho, Florianópolis, v. 9, n. 1, jan./jun. 2009.

O’REILLY, C. A.; PFEFFER, J. Talentos ocultos. Rio de Janeiro: Campus, 2001.

PAROLIN, S. R. H.; ALBUQUERQUE, L. G. Gestão de pessoas para a criatividade em organizações inovativas. Revista Eletrônica de Administração, Porto Alegre, v. 16, n. 3, set./dez. 2010.

PEDROSA, R. R. Programas de jovem talento: projeto ou processo de atração e desenvolvimento de talentos?. Um estudo de caso em empresa brasileira. 2005. Dissertação (Mestrado em Administração) - Programa de Pós-graduação em Administração, Pontifícia Universidade Católica de Minas Gerais, Belo Horizonte, 2005.

PEREIRA, L. C. B.; WHILHEIM, J.; SOLA, L. (Org.). Sociedade e estado em transformação. São Paulo: UNESP, 1999.

PONTES, B. R. Gestão de profissionais em empresas competitivas: como atrair e reter talentos. São Paulo: LTR, 2001.

SANT'ANNA, A. S. Competências individuais requeridas, modernidade organizacional e satisfação no trabalho: uma análise de organizações mineiras sob a ótica de profissionais da área de administração. 2002. Tese (Doutorado em Administração) - Faculdade de Ciências Econômicas, Universidade Federal de Minas Gerais, Belo Horizonte, 2002. 
SANTOS, A. P. Gestão do conhecimento em organizações que aprendem: gestão de competências e retenção dos talentos. In: CONGRESO INTERNACIONAL DEL CLAD SOBRE LA REFORMA DEL ESTADO Y DE LA ADMINISTRACIÓN PÚBLICA, 11., 2006, Ciudad de Guatemala. Anais... Ciudad de Guatemala: [s.n.], 2006.

SARSUR, A. M. Empregabilidade e empresabilidade?: um estudo junto a organizações e profissionais em Minas Gerais. 1999. Dissertação (Mestrado em Administração) - Faculdade de Ciências Econômicas, Universidade Federal de Minas Gerais, Belo Horizonte, 1999.

SARSUR, A. M.; PEDROSA, R. R.; SANT'ANNA, A. S. Onde estão os talentos? Onde está a gestão de recursos humanos? In: ENCONTRO NACIONAL DE PROGRAMAS DE PÓSGRADUAÇÃO EM ADMINISTRAÇÃO, 27., 2003, Atibaia. Anais... Rio de Janeiro, ANPAD, 2003.

TANURE, B.; EVANS, P.; PUCIK, V. A gestão de pessoas no Brasil: virtudes e pecados capitais. Rio de Janeiro: Elsevier, 2007.

TOLEDO, S. Carreira e identidade: reflexos das exigências mercadológicas na vida pessoal e profissional dos jovens executivos de empresas multinacionais. In: ENCONTRO NACIONAL DE PROGRAMAS DE PÓS-GRADUAÇÃO EM ADMINISTRAÇÃO, 30., 2006, Salvador. Anais... Rio de Janeiro: ANPAD, 2006.

ULRICH, D. Os campeões de recursos humanos: inovando para obter melhores resultados. São Paulo: Futura, 1998.

VIEIRA, A.; SILVA, C. J. M. Por que deixar a empresa quando tudo indica que o melhor é ficar? Revista de Ciências da Administração, Florianópolis, v. 10, n. 20, p. 37-58, jan./abr. 2008 .

YAMASHITA, L. K. Fatores de influência na retenção de talentos em empresas de distribuição de energia elétrica: um estudo de caso. 2006. Dissertação (Mestrado em Administração) - Programa de Pós-graduação em Administração, Pontifícia Universidade Católica de Minas Gerais, Belo Horizonte, 2006.

YIN, R. K. Estudo de caso: planejamento e métodos. Porto Alegre: Bookman, 2001. 